\title{
ATUAÇÃO DOS PSICÓLOGOS QUE TRABALHAM EM EMPRESAS QUE DESENVOLVEM PROGRAMAS DE QUALIDADE
}

\author{
Adriana Pellanda Gagno ${ }^{* *}$ \\ Eliana de Paula Congro Venturi
}

\begin{abstract}
RESUMO
As aceleradas transformações por que o mundo do trabalho vem passando, devido à globalização da economia, estão construindo um novo paradigma organizacional, marcado pela busca da Qualidade Total (QT) e da produtividade. O presente estudo exploratório procura conhecer a atuação dos psicólogos organizacionais que atuam num programa de QT. Os sujeitos são vinte psicólogos atuando há cerca de um ano ou mais em organizações multinacionais e/ou privadas de Curitiba. Entrevistas semiestruturadas com os sujeitos possibilitam a obtenção das informações que são gravadas, posteriormente categorizadas e analisadas quantitativa e qualitativamente. A análise de dados revela como principais os seguintes resultados: as dificuldades encontradas pelo psicólogo para ser
\end{abstract}

Trabalho apresentado no IV Evento de Científica - EVINCI/96, promovido pela PróReitoria de Pesquisa e Pós-Graduação da Universidade Federal do Paraná, de 4 a 6 de setembro de 1996, sendo premiado com o $3^{\circ}$ lugar da Comissão da subárea de Ciências Humanas.

** Bolsista de Iniciação Científica CNPq/UFPR.

*** Professora do Departamento de Psicologia da Universidade Federal do Paraná; Mestre Dela UFPR em Educação - área de concentração de Recursos Humanos.

Interação, Curitiba, v. 1, p. 43-72, jan./dez. 1997 
um agente de transformação referem-se à área comportamental e não a processos; os psicólogos desenvolvem tanto atividades técnicas quanto de consultoria; participam do Programa de Qualidade por esta ser uma exigência da empresa; consideram essencial sua atuação no programa devido aos conhecimentos humanos e psicológicos que dizem possuir, porém apenas $20 \%$ deles têm pressupostos teóricos claros de Psicologia subsidiando sua prática. Conclui-se que estes psicólogos começam a modificar sua prática devido à pressão da nova realidade organizacional, contudo sua inconsistência teórica é um fator que dificulta a saída da atuação técnica tradicional para a ocupação do espaço que se abre a partir das atuais necessidades de mudança comportamental - objeto este de estudo e trabalho do profissional psicólogo.

\section{INTRODUÇÃO}

As aceleradas transformações por que o mundo do trabalho vem passando, devido ao informacionalismo e à globalização da economia, estão construindo um novo paradigma organizacional, marcado pela busca da melhoria de qualidade, com base numa gestão participativa. A busca da Qualidade Total (ou da Melhoria de Qualidade) e da produtividade tornaram-se fatores indispensáveis à sobrevivência das empresas.

Para atingir tais objetivos, as mudanças necessárias dizem respeito mais aos indivíduos do que às ferramentas. Mudanças de atitudes, de comportamento e de cultura constituem exatamente o objeto de estudo e de trabalho da Psicologia.

A Qualidade Total abre, portanto, para o profissional psicólogo, amplas oportunidades de atuação organizacional e exige dele um papel diferente daquele tradicionalmente desempenhado.

Qual a participação do psicólogo neste momento em que as organizações estão mudando? 


\section{Qual sua contribuição para esses programas?}

Que fatores levaram o psicólogo a participar das mudanças geradas pela implantação do Programa de Qualidade?

Quais as dificuldades mais freqüentes que o psicólogo enfrenta, para ser agente de transformação na empresa?

Quais os requisitos e habilidades consideradas mais importantes para que ele possa melhor atender às expectativas do seu cargo?

Estes questionamentos despertaram o interesse por conhecer o que os psicólogos estão fazendo, na prática, neste novo contexto.

As informações obtidas a partir dessa avaliação, da contribuição do psicólogo nas empresas com programas de qualidade total, serão de grande valia para possibilitar reestruturações no currículo dos cursos de formação em Psicologia e para se tomar conhecimento do estágio de conscientização da própria carreira do psicólogo organizacional. Esta conscientização tem um potencial remodelador, na medida em que pode estimular um redirecionamento qualitativo da profissão: uma delimitação do papel na organização facilitaria, segundo GONÇALVES, "sua autodireção e uma conscientização dos dirigentes e outros profissionais" (1992, p. 24).

Diante do quadro de macrotransformações que vêm ocorrendo no mundo do trabalho, torna-se necessária uma breve revisão histórica da atuação do psicólogo neste campo.

A Psicologia do Trabalho nasceu, segundo MALVEZZI (1992), das necessidades advindas de uma mudança de tecnologia, como estamos vivendo hoje.

Quando do seu surgimento, no começo do século XX, os psicólogos eram chamados a contribuir com a compreensão dos determinantes do desempenho no trabalho, o que levou a uma predominância da Psicometria. Num segundo momento, o psicólogo extrapola o nível individual e procura centrar-se no grupo, levando em conta as variáveis organizacionais no ajustamento do 
homem ao trabalho. E, no terceiro período em que se pode dividir a Psicologia Organizacional, o psicólogo passa a atuar com os processos sociocomportamentais, a partir de uma visão sistêmica da organização.

A atuação tradicional do psicólogo - voltada exclusivamente para atividades técnicas especializadas (por exemplo, atuação em recrutamento e seleção, treinamento, avaliação de desempenho, etc.) - não é mais condizente com as necessidades organizacionais atuais.

O profissional psicólogo deve ter em mente que, na equipe multiprofissional na qual trabalha - o Departamento de Recursos Humanos -, há economistas, administradores, engenheiros que precisam da sua colaboração para melhor atuarem no conjunto da organização. Sua interação é fundamental. Seu mundo profissional deve ser o da empresa e não o do isolamento de seu gabinete. A organização atual precisa de um psicólogo que assuma responsabilidades e seja competente ao fazer a "leitura" da realidade organizacional, da multideterminação dos comportamentos dos funcionários, dos fatores que mais estão afetando a motivação dos mesmos, dos conflitos, da competição pelo poder, das relações interpessoais, das relações trabalhistas, do comprometimento das pessoas e de seu grau de resistência às mudanças; e que esteja, além disso, sempre atento às perspectivas teóricas que embasam sua prática, consciente do seu papel político dentro da empresa, numa constante reavaliação da sua atuação.

É neste novo contexto de Qualidade Total - que lida diretamente com as mudanças comportamentais e de cultura - que se abre para o psicólogo um vasto campo de atuação, devido à sua melhor e mais completa formação sobre comportamento humano, entre os demais profissionais da empresa.

Dentro de um programa de QT, o aspecto comportamental é muito mais importante que o aspecto tecnológico. São as pessoas que fazem a qualidade, sem o seu envolvimento não há mudança organizacional. 
Por isso, é fundamental despir-se dos modelos interiorizados do passado e reproduzidos sem uma análise das exigências e oportunidades atuais. Certamente, esta superação só será obtida se o psicólogo investir em sua própria formação e no seu autodesenvolvimento.

A literatura (BASTOS, 1992 e ZANELLI, 1994) já aponta como uma tendência emergente em Psicologia Organizacional o rompimento do nível técnico de atuação e a busca de uma visão ampliada da prática. "A permanência do nível técnico, em qualquer situação, dificulta ao psicólogo perceber possibilidades de inserção, de estar integrado no nível do planejamento estratégico e o faz mantenedor ao invés de agente de mudanças" (ZANELLI, 1994, p. 110). Este movimento, contudo, ainda é incipiente, posto que poucos psicólogos estão conseguindo lidar com as novas solicitações organizacionais. VENTURI (1992) constata que, em Curitiba, a atuação do psicólogo organizacional é também muito centrada em recrutamento, seleção e treinamento, sendo pequeno $(8,86 \%)$ o número de psicólogos que conseguem intervir nos processos decisórios e exercer alguma influência em nível de planejamento, ou mesmo participação nas decisões políticas da empresa. Estas limitações advêm, principalmente, das falhas na formação, da pouca produção científica na área, da ignorância organizacional do papel do psicólogo e do desinteresse pelas atividades de aplicação da Psicologia nas organizações.

Um psicólogo integrado com as novas solicitações da sua profissão deveria buscar, entre outras coisas:

- atualizar-se sobre as modernas técnicas de gestão organizacional;

- estar sintonizado com as mudanças sociais que se impõem (como a globalização da economia);

- trocar experiências profissionais, participando de debates e discussões;

- conhecer o negócio da empresa em que atua; 
- antecipar-se às mudanças;

- envolver-se no planejamento estratégico;

- utilizar seus conhecimentos para melhorar a qualidade de vida dos funcionários na empresa;

- assessorar a direção da empresa em planejar seus recursos humanos;

- ser criativo;

- exercer a liderança;

- ter flexibilidade para a atuação;

- trabalhar as resistências à mudança, esclarecendo os motivos que geraram a necessidade de mudança e os benefícios decorrentes dessa nova situação.

É preciso que o psicólogo repense seu papel profissional e não restrinja sua atuação a uma mera reprodução daquilo que aprendeu na universidade. Se não modificar sua postura, alcançando posições de influência em nível decisório, tornar-se-á um profissional dispensável nas organizações e perderá o espaço já conquistado.

Conhecer a atuação dos psicólogos organizacionais tendo como contexto empresas que desenvolvem Programas de Qualidade, representa o objetivo da presente pesquisa.

\section{MÉTODO}

Os dados aqui apresentados fazem parte de um estudo mais amplo, que contém também a opinião dos responsáveis pelos Programas de Qualidade sobre a atuação do psicólogo nestas empresas. Este relato restringir-se-á a expressar a visão dos psicólogos.

Sujeitos: Participaram deste estudo exploratório vinte psicólogos envolvidos em Programa de Qualidade, que atuavam há cerca de um ano ou mais em dezesseis organizações multinacionais e/ou privadas de Curitiba. Os sujeitos foram selecionados a partir de 143 empresas, das quais apenas 16 desenvolviam Pro- 
gramas de Qualidade e tinham psicólogos em seus quadros de pessoal.

Instrumento: Foi utilizado para coleta de dados um roteiro de entrevista, dirigido aos psicólogos, que continha dezenove questões versando sobre os seguintes temas: caracterização dos psicólogos; atividades desempenhadas pelos mesmos; fatores que os levaram a participar das mudanças geradas pelo Programa de Qualidade; dificuldades que encontraram para serem agentes de transformação nas empresas; requisitos necessários para uma boa atuação dos psicólogos envolvidos no Programa de Qualidade; percepção da sua atuação no Programa de Qualidade e existência de pressupostos teóricos na prática destes profissionais.

Procedimento: As entrevistas foram realizadas pessoalmente pelas pesquisadoras e tiveram duração de uma hora; os relatos foram gravados e depois transcritos.

\section{RESULTADOS}

Foi calculada a freqüência das respostas, suas percentagens e médias ponderadas. Para algumas destas questões, o número de respostas (e não o número de sujeitos) equivale a $100 \%$. Isto significa que cada resposta foi analisada exaustivamente, de maneira a ser enquadrada em tantas categorias quantas fossem necessárias para esgotar seu conteúdo, respeitado o critério de não se repetirem numa mesma categoria duas respostas equivalentes, dadas por um mesmo sujeito.

\subsection{CARACTERIZAÇÃO DOS PSICÓLOGOS}

\subsubsection{Sexo}

O total dos psicólogos é de dezesseis $(80 \%)$ mulheres e quatro $(20 \%)$ homens. 


\subsubsection{Idade}

Dentre os psicólogos entrevistados, dez (50\%) têm entre trinta e um a quarenta anos, oito (40\%) têm até trinta anos e dois (10\%) têm mais de quarenta anos.

\subsubsection{Instituição de Ensino onde se Formaram}

A instituição de ensino que formou a maioria dos entrevistados foi a Faculdade de Ciências e Letras TUIUTI (nove psicólogos - 45\%), seguida da PUC-PR (quatro psicólogos - 20\%) e da UFPR (três psicólogos - $15 \%)$. Outras quatro $(20 \%)$ instituições de ensino foram mencionadas pelos demais entrevistados.

\subsubsection{Qualificação Acadêmica}

Constatou-se que doze (60\%) psicólogos completaram sua formação acadêmica com um curso de especialização e quatro $(20 \%)$ com mais de uma especialização. Somente três (15\%) psicólogos possuem apenas graduação e um (5\%) psicólogo está cursando especialização.

\subsubsection{Tempo de Formação}

Pode-se verificar na Tabela 1 que a maior parte (oito psicólogos - $40 \%$ ) formou-se no tempo de seis a dez anos.

\section{TABELA 1 - PORCENTAGEM DE RESPOSTAS DOS PSICÓLOGOS QUANTO AO TEMPO EM QUE ESTÃO FORMADOS}

\begin{tabular}{lcc}
\hline TEMPO DE FORMAÇÃO & F & $\%$ \\
\hline 1 a 5 anos & 7 & 35,00 \\
6 a 10 anos & 8 & 40,00 \\
11 a 15 anos & 2 & 10,00 \\
mais de 15 anos & 3 & 15,00 \\
\hline TOTAL & 20 & 100,00
\end{tabular}




\subsubsection{Tempo de Trabalho na Atual Empresa}

A maior parte $(75 \%)$ dos psicólogos trabalha na atual empresa há menos de cinco anos; três (15\%) trabalham de seis a dez anos; dois (10\%) trabalham de onze a quinze anos.

\subsubsection{Cargo}

Apenas um (5\%) entrevistado atua no cargo de psicólogo. Grande parte (oito psicólogos - 40\%), atua como analista de recursos humanos e os demais atuam nos seguintes cargos: analista de recrutamento, seleção e treinamento; supervisor de desenvolvimento de pessoal; chefe de seção de serviços gerais; assessor de qualidade; analista de treinamento; chefe e desenvolvimento de $\mathrm{RH}$; encarregado de recrutamento, seleção, treinamento e administração de pessoal; supervisor de $\mathrm{RH}$; encarregado de seleção e treinamento; supervisor de desenvolvimento de $\mathrm{RH}$.

\subsubsection{Participação no Comitê de Qualidade}

Dentre os entrevistados, treze (65\%) participam do comitê de qualidade, seis (30\%) não participam e um (5\%) afirmou que na empresa em que trabalha não há um comitê desta natureza.

\subsection{ATIVIDADES DESEMPENHADAS PELOS PSICÓLOGOS}

As alternativas mostradas na Tabela 2, referentes às atividades que os psicólogos realizam na empresa, foram respondidas de acordo com a intensidade com que são desempenhadas. Foram agrupadas numa mesma categoria as atividades muito realizadas ou realizadas com freqüência média e as pouco ou não realizadas.

De acordo com a Tabela 2, verifica-se que a maioria absoluta não realiza ou realiza com pouca freqüência a maior parte das atividades referentes à alocação de pessoal, como recrutamento de pessoal $(75 \%)$, seleção de pessoal utilizando testes específicos e/ou entrevista (65\%), seleção de pessoal utilizando testes psicológicos $(75 \%)$, seleção com uso de grafologia (75\%). 


\section{TABELA 2 - DISTRIBUIÇÃO DAS ATIVIDADES QUE OS PSICÓLOGOS REALIZAM NA EMPRESA}

\begin{tabular}{|c|c|c|c|c|}
\hline INTENSIDADE & MUITO & MEDIO & POUCO & NADA \\
\hline ATIVIDADES & $f$ & $\%$ & $t$ & $\%$ \\
\hline Efetua recrutamento de pessoal & 5 & 25,00 & 15 & 75,00 \\
\hline Seleciona pessoal com testes especificos e/ou entrevista & 7 & 35,00 & 13 & 65,00 \\
\hline Seleciona pessoal com testes psicológicos & 5 & 25,00 & 15 & 75,00 \\
\hline Seleciona pessoal com grafologia & 5 & 25,00 & 15 & 75,00 \\
\hline Faz acompanhamento de pessoal & 15 & 75,00 & 5 & 25,00 \\
\hline Diagnostica necessidade de treinamento & 16 & 80,00 & 4 & 20,00 \\
\hline Planeja treinamento & 19 & 95,00 & 1 & 5,00 \\
\hline Aplica treinamento & 15 & 75,00 & 5 & 25,00 \\
\hline Avalia treinamento & 19 & 95,00 & 5 & 5,00 \\
\hline Faz avaliação de desempenho & 16 & 80,00 & 4 & 20,00 \\
\hline Elabora proj. saúde ocup. & 4 & 20,00 & 16 & 80,00 \\
\hline Realiza aconselhamento individual & 7 & 5,00 & 19 & 95,00 \\
\hline Contribui na segurança e higiene do trabalho & 7 & 35,00 & 13 & 65,00 \\
\hline Realiza remanejamento de pessoal & 9 & 45,00 & 11 & 55,00 \\
\hline Faz diagnóstico institucional & 9 & 45,00 & 11 & 55,00 \\
\hline Realiza planos de carreira & 9 & 45,00 & 11 & 55,00 \\
\hline Desenvolve politicas de RH & 14 & 70,00 & 6 & 30,00 \\
\hline Faz entrevista de desligamento , & 9 & 45,00 & 11 & 55,00 \\
\hline Valida instrumentos de mensuraçáo psicológica & 7 & 35,00 & 13 & 65,00 \\
\hline Atualiza planos de cargos e salários & 5 & 25,00 & 15 & 75,00 \\
\hline Atua em ergonomia & 2 & 10,00 & 18 & 90,00 \\
\hline Atua em consultoria interna & 16 & 80,00 & 4 & 20,00 \\
\hline Participa do planejamento estratégico & 12 & 60,00 & 8 & 40,00 \\
\hline Supervisiona atividades técnicas em Psicologia & 6 & 30,00 & 14 & 70,00 \\
\hline Elabora e realiza pesquisas & 13 & 65,00 & 7 & 35,00 \\
\hline Participa de um time de qualidade & 16 & 80,00 & 4 & 20,00 \\
\hline Atua em desenvolvimento organizacional & 14 & 70,00 & 6 & 30,00 \\
\hline
\end{tabular}

*As atividades relacionadas na tabela acima năo såo mutuamente excludentes. 
Já a atividade de acompanhamento de pessoal é realizada com muita freqüência ou com freqüência média por $75 \%$ dos entrevistados.

Quanto às atividades relacionadas com o treinamento, podese verificar que são as mais freqüentemente realizadas dentre todas as atividades listadas, atingindo os seguintes índices: aplicação de treinamento (75\%), diagnóstico das necessidades de treinamento (80\%), planejamento do treinamento $(95 \%)$ e avaliação de treinamento (95\%).

A avaliação de desempenho é uma atividade pouco ou não realizada pela maioria absoluta $(70 \%)$ dos entrevistados.

Quanto às atividades referentes à promoção da saúde do trabalhador, observa-se que são realizadas com pouca freqüência ou não são realizadas as atividades de elaboração de projetos que envolvem a saúde ocupacional (80\%), participação na segurança e higiene do trabalho (65\%). Verifica-se que aconselhamento psicológico individual - atividade realmente desvinculada da área organizacional - praticamente não é realizado.

Dentre as outras atividades realizadas pelos psicólogos entrevistados, obtiveram maioria absoluta de realização, com freqüência grande ou média, as seguintes: desenvolvimento de políticas de $\mathrm{RH}(70 \%)$, atuação em consultoria interna (80\%), participação no planejamento estratégico $(60 \%)$, elaboração e realização de pesquisas visando dar subsídios à organização (65\%), participação em um time de qualidade $(80 \%)$, atuação em desenvolvimento organizacional (70\%).

Foram também especificadas as seguintes atividades relativas à Qualidade Total: assessoria aos grupos de padronização e coordenação de projetos dentro do Programa de Qualidade.

Os passos da qualidade, segundo CROSBY (1995), realizados com a maior freqüência pelos psicólogos são: educação, em 1 lugar, sendo realizado por dezoito entrevistados (90\%); participação numa equipe de melhoria de qualidade, em $2^{\circ}$ lugar, sendo 
realizado por doze (60\%) entrevistados. Em $3^{\circ}$ lugar, empatam, com dez entrevistados, a realização de atividades voltadas à consciência da qualidade $(50 \%)$ e ao reconhecimento $(50 \%)$ - o que será comentado adiante.

Quanto à abrangência da atuação do psicólogo em relação aos níveis hierárquicos da empresa, constatou-se que a maior parte $(50 \%)$ dos psicólogos entrevistados atingem com sua atuação a alta administração, a gerência de processos e os funcionários; seis $(30 \%)$ atingem apenas os funcionários; dois (10\%) atinge a gerência de processos e os funcionários; um (15\%) atinge somente a alta administração e um (15\%) atinge apenas o nível de gerência.

\subsection{FATORES QUE LEVARAM OS PSICÓLOGOS A PARTICIPAR DAS MUDANÇAS GERADAS PELO PROGRAMA DE QUALIDADE}

De maneira geral, os psicólogos justificaram estar participando do Programa de Melhoria da Qualidade por esta ser uma demanda da empresa. Acreditam que esta demanda se deve ao fato de fazerem parte da área de Recursos Humanos, terem conhecimento acerca de mudanças comportamentais e por serem responsáveis pelo treinamento - aspectos vitais para o desenvolvimento de um programa que leva à mudança organizacional. Os psicólogos relatam terem-se conscientizado sobre a necessidade de mudança a partir desta solicitação da empresa. Apenas dois entrevistados disseram que foi uma iniciativa pessoal trabalhar com a qualidade, sendo que um deles destacou que sua iniciativa se deveu à percepção de que no contexto de mudanças em que estava inserido poderia melhor utilizar sua formação em Psicologia. 


\subsection{DIFICULDADES ENCONTRADAS PELOS PSICÓLOGOS PARA SEREM AGENTES DE TRANSFORMAÇÃO NAS EMPRESAS}

É interessante notar, na Tabela 3, que, do total de psicólogos entrevistados, $90 \%$ afirmaram que enfrentam obstáculos para serem agentes de mudança.

$\begin{aligned} & \text { TABELA } 3 \text { - PORCENTAGEM DE RESPOSTAS DOS PSICÓLOGOS } \\
& \text { REFERENTES AOS OBSTÁCULOS QUE ENFRENTAM } \\
& \text { PARA SEREM AGENTES DE TRANSFORMAÇÃO NA } \\
& \text { EMPRESA }\end{aligned}$
\begin{tabular}{lcr} 
& & \\
\hline OBSTÁCULOS & F & $\%$ \\
\hline Resistência a mudanças & 13 & 65,00 \\
Política da empresa & 2 & 10,00 \\
Falta de tempo devido às tarefas administrativas & 2 & 10,00 \\
Não falar a mesma linguagem que a alta administração & 1 & 5,00 \\
Não citam obstáculos & 2 & 10,00 \\
\hline TOTAL & 20 & 100,00
\end{tabular}

A resposta mais citada, por treze (65\%) psicólogos, foi que a resistência à mudança é o maior obstáculo a ser vencido, pois está presente em todos os níveis, desde a alta administração até a base. Parte dessa resistência deve-se às pessoas não estarem conscientes da sua importância no processo de mudança.

Vale a pena salientar que: a política da empresa; a falta de tempo do psicólogo (devido a outras atividades técnicas e administrativas exigirem total empenho); a dificuldade de o psicólogo falar a mesma linguagem que a alta administração e as falhas na formação (cujo enfoque é apontado como preponderantemente clínico) também atrapalham o processo de mudança.

Os depoimentos abaixo ilustram deficiências encontradas na formação do psicólogo organizacional:

a) "Acho que abriu um campo muito grande pro psicólogo. Se ele for esperto e enxergar que abriu esse campo, da 
qualidade. ... Hoje se valoriza mais o $\mathrm{RH}$ por causa da Qualidade. (...) Se o psicólogo se especializar em qualidade não vão faltar oportunidades. Isso aí é uma coisa de necessidade mesmo da empresa sobreviver";

b) "... normalmente, quando chega um estudante de psicologia aqui, ele não sabe nem o que ele pode fazer numa indústria, que é tão pouco que isso é passado no currículo escolar. O que você tem lá? Tem um pouquinho de avaliação de desempenho, mas uma coisa muito rapidamente, tem como se faz uma pesquisa de clima organizacional, recrutamento e seleção forte, teste, teste, teste. Mas não é só isso que psicólogo pode fazer, ele pode ficar em muitas frentes. Acho que aí é que tá o grande filão que deve ser descoberto pelo profissional de Psicologia";

c) "O que a gente vê dentro do trabalho voltado para a Psicologia, ainda os cursos de Psicologia estão muito voltados à área clínica, ao atendimento individual, e há uma carência muito grande nas organizações. Então, o que a gente vê de profissional fazendo o trabalho de forma errada dentro das organizações (...) eu digo que isso já é uma carência de formação. É por isso que a gente vê muito psicólogo em organização se queimando, se complicando e atrapalhando o desenvolvimento da organização e não atuando, mostrando o que realmente precisa atuar na organização. Então por isso que tem muitos empresários que têm aversão a psicólogos, a assistente social e outras pessoas ligadas à área humana. (...) Então, nesse sentido, eu acho importante se dar essa ênfase na formação do psicólogo, pra ver realmente o papel e ver o quanto é importante a atuação do psicólogo e até abrir um vasto campo de trabalho dentro do campo da Psicologia". 


\subsection{REQUISITOS NECESSÁRIOS PARA UMA BOA ATUAÇÃO DOS PSICÓLOGOS ENVOLVIDOS NO PROGRAMA DE QUALIDADE}

Os requisitos e habilidades que foram classificados como mais importantes para uma boa atuação dos psicólogos envolvidos nos Programas de Qualidade foram, nesta ordem: visão global do negócio (em 1ำ lugar); flexibilidade para atuação (em $2^{\circ}$ lugar) e, quase empatados na $3^{a}$ colocação, capacidade de antecipar-se às mudanças; habilidades em administração de conflitos e envolvimento no planejamento estratégico.

\subsection{PERCEPÇÃO DA SUA ATUAÇÃO NO PROGRAMA DE QUALIDADE}

A grande maioria (80\%) considerou sua atuação "necessária", "forte", "importante", "comprometida", "essencial", "ativa", "fundamental", devido ao seu conhecimento do ser humano e do comportamento (que são utilizados para desenvolver a motivação, a sensibilização para a qualidade, para fazer a leitura dos grupos, dar suporte às gerências, participar do planejamento estratégico). Salienta-se que dos quatro psicólogos (20\%) que consideraram sua contribuição "limitada", "mínima", "pequena", três atribuem o motivo ao fato de a empresa não estar investindo muito no Programa de Qualidade no momento, e um disse "haver espaço para uma maior participação de sua parte, mas que ainda não está ocupando esse espaço".

\subsection{EXISTÊNCIA DE PRESSUPOSTOS TEÓRICOS NA PRÁTICA DESTES PSICÓLOGOS}

A fim de verificar a existência de fundamentação teórica subsidiando a prática destes psicólogos foram investigadas: as teorias que norteiam sua atuação; a sua visão acerca de mudanças de comportamento, atitudes e cultura; a sua concepção de 
qualidade no que tange às relações indivíduos versus organização e o seu nível de intervenção (psicológico, administrativo, etc.).

De acordo com a Tabela 4, apenas quatro (20\%) psicólogos têm uma teoria psicológica clara e definida subsidiando sua atuação.

\begin{tabular}{|c|c|c|}
\hline PRESSUPOSTOS TEÓRICOS & $\mathrm{F}$ & $\%$ \\
\hline $\begin{array}{l}\text { Apresentam uma "mistura" de conceitos psicológicos e organi- } \\
\text { zacionais incompatíveis entre si, errôneos ou estanques }\end{array}$ & 7 & 35,00 \\
\hline Usam apenas teorias de Oualidade & 4 & 20,00 \\
\hline Têm teoria psicológica clara e definida & 4 & 20,00 \\
\hline $\begin{array}{l}\text { Apresentam conceitos de Qualidade somados à teoria do } \\
\text { conhecimento }\end{array}$ & 1 & 6,00 \\
\hline TOTAL & 20 & 100,00 \\
\hline
\end{tabular}

Os relatos abaixo revelam tal inconsistência teórica:

a) "Eu vejo que a todo momento a gente atua em todos sentidos, não tem uma teoria específica. (...) Acho assim que é uma grande salada de teoria onde, a todo momento você, às vezes, está até atuando mas não sabe nem que teoria que é, aí, de repente, 'olha, essa teoria é aquela que aprendi em tal lugar'”;

b) "Não tem escola de Administração ou Psicologia, já usei uma parte de Gestalt e Jung para fazer um sistema de avaliação de perfil, mas a gente não segue porque não tem como seguir. Dependendo da situação, do momento, do que você tenha que fazer, você tem que seguir para uma linha, então não pode ser assim uma linha definida";

c) "Nós não nos baseamos em nenhuma teoria, em nenhum conceito. Na realidade nós procuramos, a princípio, tentar arrumar a casa do jeito que dava mesmo, mas mesmo no administrativo nós não chegamos a nenhuma teo- 
ria. Eu acredito que vai ser a segunda parte do programa, nós vamos precisar mesmo, vamos verificar";

d) "Eu não costumo, na verdade, atuar em cima de grandes filosofias e grandes teorias para colocar o meu trabalho em prática. Acho que a teoria ajuda pra você se atualizar...";

e) “... a gente não está indo muito atrás de teorias, de livros, a gente está indo atrás da realidade, do que está acontecendo";

f) "... utilizo conceitos básicos da formação, como por exemplo conceitos de percepção, de ser humano, que influenciam de forma indireta, de maneira geral; não conceitos específicos de autores".

Os entrevistados acreditam nas mudanças comportamentais, de atitudes e de cultura apesar de considerarem-nas um desafio. Citam a pressão exercida pela globalização da economia como impulsionador e determinante das mudanças. Abordam, de maneira geral, a importância de esclarecer as pessoas sobre 0 porquê da necessidade de transformação e consideram-na mais eficaz se houver a ação estratégica voltada para este foco. É interessante destacar que um psicólogo não compreendeu o que significa "cultura organizacional", relacionando seu conceito à escolaridade.

A concepção que os entrevistados têm de qualidade, na inter-relação entre indivíduos e organização remete à visão da qualidade de vida, que a qualidade deve ser incorporada pelo indivíduo para depois ser aplicada também no contexto profissional. Um psicólogo (5\%) mencionou a mudança da relação capitaltrabalho, gerada pelo movimento da Qualidade, que torna a relação entre empresa e empregado uma parceria.

Quanto ao nível de intervenção, doze (60\%) consideram como sendo tanto psicológico quanto administrativo; seis (30\%) consideraram apenas administrativo; um (5\%) considerou apenas 
psicológico e um (5\%) considerou sua intervenção como sendo uma assessoria didática.

\section{DISCUSSÃO DOS RESULTADOS}

Verificou-se que a grande maioria dos psicólogos envolvidos em Programas de Qualidade procurou aprimorar sua qualificação acadêmica tendo cursado especialização em Recursos Humanos $(\mathrm{RH})$. Isso revela um mercado exigente que estimula o desenvolvimento profissional e pode revelar que a formação acadêmica disponível para a formação desse psicólogo não atende às necessidades do mercado.

É interessante notar que apenas um (5\%) entrevistado foi contratado para o cargo de psicólogo, sendo que os demais receberam diversas denominações para o cargo, variando de "encarregado de seleção e treinamento" a "assessor da qualidade", podendo ser tal denominação um fator de restrição ou ampliação das possíveis atividades a serem desempenhadas.

Alguns entrevistados também mencionaram que não é preciso ser psicólogo para fazer o que estão fazendo mas, ao mesmo tempo, salientaram a importância do trabalho na empresa ser desenvolvido numa equipe multidisciplinar - logo, onde cada um tem um conhecimento específico para contribuir com o grupo.

Estes dados levam à reflexão sobre a conflitante imagem que o psicólogo organizacional tem de sua própria identidade profissional.

$\mathrm{Na}$ opinião dos psicólogos (em média $85 \%$ ) as atividades que mais realizam são as referentes ao treinamento, tais como diagnóstico de necessidades, planejamento, aplicação e avaliação de treinamento.

No atual contexto de Qualidade, o treinamento vem recebendo grande destaque por ser um dos requisitos necessários à obtenção do certificado da ISO 9000 e para a efetivação de qualquer movimento de busca da melhoria da qualidade. 
Neste ponto, o psicólogo organizacional pode auxiliar pois ele é especialista em comportamento organizacional. A tensão criada entre o que é conhecido e já estabelecido e aquilo que surge como novo pode ser trabalhada pelo psicólogo, que inserido no processo de qualidade ajuda as pessoas a inovar, antecipar, gerar qualidade e excelência.

As outras atividades mais citadas pelos psicólogos como sendo realizadas com uma freqüência média ou grande são: acompanhamento de pessoal (75\%), desenvolvimento de políticas de $\mathrm{RH}(70 \%)$, participação em um time de qualidade $(80 \%)$ e consultoria interna (80\%). Isto revela a conquista de uma posição mais influente na organização.

Infelizmente, os dados da pesquisa não permitiram relacionar quais são as atividades básicas do consultor interno, o que seria interessante, pois pode haver entre os psicólogos visões diferentes acerca das atividades que envolvem consultoria interna. Mesmo assim, tal porcentagem é bastante superior aos 20,25\% obtidos por VENTURI (1992) junto aos psicólogos organizacionais de Curitiba (população esta não restrita aos psicólogos envolvidos com Programas de Qualidade), que desempenhavam esta atividade com freqüência média ou grande. Esta percentagem pode demonstrar que os psicólogos envolvidos em Programas de Qualidade, via de regra, estão sendo mais solicitados a colaborar na dinâmica organizacional.

Quanto à consultoria interna, WANDERLEY (1992) afirma que a máxima "santo de casa não faz milagre" representa um enfoque que começa a sair de uso. Este início de mudança, da utilização dos serviços de consultores externos para os de consultores internos, tem como fatores precipitadores, segundo o autor, a necessidade de contenção de custos; a maior proximidade que 0 consultor interno tem dos problemas da empresa e o maior conhecimento que tem dos seus valores e cultura; a existência de atividades que, embora geralmente não sejam efetuadas dentro 
de uma perspectiva de consultaria, poderiam passar a sê-lo, como as de auditoria, por exemplo, entre outras.

Apesar de não possuir informações sobre as atividades específicas desenvolvidas por estes psicólogos enquanto consultores internos, tentou-se desenhar o seu perfil, explicitando-se quais são os requisitos e habilidades "ideais" do psicólogo que atua em Programas de Qualidade - o que será comentado posteriormente.

Outro dado significativo é o que revela uma diminuição do número de psicólogos que realizam recrutamento e seleção de pessoal, dentro do grupo pesquisado, salientando que o envolvimento com a Qualidade conduz este profissional a uma atuação diferenciada.

A utilização de testes psicológicos também apresenta-se bem menos freqüente entre os psicólogos envolvidos com programas de qualidade do que entre os psicólogos em geral. Dados da presente pesquisa revelam que $35 \%$ dos psicólogos realizam validação de instrumentos de mensuração psicológica e $25 \%$ fazem seleção de pessoal com uso de testes psicológicos, com freqüência média ou grande, enquanto que $45,57 \%$ e $37,97 \%$ dos psicólogos organizacionais em geral realizam tais atividades, com esta freqüência, respectivamente (VENTURI, 1992, p. 136-138). Deve-se ressaltar que o uso de testes psicológicos, antigamente, era um instrumento de poder do psicólogo na organização. Hoje, a maneira de usar esses instrumentais mudou, podendo contribuir com o desenvolvimento do ser humano, a partir do levantamento do potencial dos funcionários. E, muitas vezes, o uso de testes psicológicos na seleção de pessoal está sendo substituído por outros procedimentos, tais como entrevistas e dinâmicas de grupo.

Observa-se um alto índice de psicólogos (60\%) que afirmam participar do planejamento estratégico. Este dado é reforçado pelo que aponta como apenas $30 \%$ o número de psicólogos cuja atuação se restringe apenas aos funcionários, não atingindo outros 
níveis hierárquicos, como a gerência de processos e a alta administração.

Ressalta-se que, dos vinte psicólogos entrevistados, onze realizam outras atividades diretamente relacionadas ao Programa de Qualidade, além das já mencionadas anteriormente. Essas atividades referem-se basicamente à assessoria aos grupos de padronização e à coordenação de projetos dentro do programa de melhoria de qualidade.

Quanto à atuação específica no programa de melhoria de qualidade, agora tendo por referência os passos da qualidade, segundo CROSBY (1995), destaca-se que a atividade expressivamente mais realizada é a "educação" $(90 \%)$, isto é, o treinamento. Em seguida apresentam-se a "participação em uma equipe de melhoria de qualidade" (60\%), a realização de atividades voltadas à "consciência da qualidade" (50\%) e o reconhecimento" $(50 \%)$ - entendido como demonstração de gratidão e de percepção da importância do colaborador (funcionário) no processo, por parte da alta administração, além do reconhecimento entre os próprios funcionários, posto que numa relação de parceria um colaborador é "cliente" do outro, sendo a responsabilidade atribuída às pessoas referente a um resultado final e não a uma atividade isolada. Cabe registrar que os passos da qualidade de Crosby foram utilizados apenas como referencial de andamento dos programas, visto que só algumas empresas utilizam seus conceitos como base de trabalho. Daí a pequena freqüência com que os passos "planejamento do zero defeitos" e "dia do zero defeitos" especifidades de Crosby - foram mencionados como já incorporados pelas empresas.

O conjunto desses dados revela que os psicólogos entrevistados começam a romper com o modelo de atuação tradicional no campo do trabalho, atuação esta que se referia quase que exclusivamente às atividades técnicas relacionadas ao Recrutamento e Seleção, Acompanhamento de Pessoal, Treinamento e 
Análise de Função - como verificou CARVALHO (1988, p. 228) e VENTURI (1992, p. 84).

Essas mudanças de atuação se devem, na visão dos psicólogos entrevistados, a uma exigência das empresas. Acreditam que esta demanda de incremento nas atividades desempenhadas é dirigida ao órgão de $\mathrm{RH}$ e, conseqüentemente, ao psicólogo nele inserido. Os psicólogos foram quase unânimes ao afirmar que a "onda da qualidade", decorrente da globalização, tem pressionado as mudanças organizacionais e, com isto, as novas formas de gestão do trabalho.

Esses psicólogos que desenvolvem programas de qualidade destacaram quase por unanimidade que a influência exercida pelo $\mathrm{RH}$ no contexto de qualidade é estratégica. É interessante salientar que este dado revela uma realidade bem diferente da observada por VENTURI (1992) que constatou que, para 59,50\% dos psicólogos organizacionais, em geral, a influência do departamento, setor ou gerência de $\mathrm{RH}$ nas decisões estratégicas e políticas da empresa é pouca, pouquíssima ou inexistente.

Essa discrepância na percepção da influência exercida pelo $\mathrm{RH}$ é justificável, devido haver atualmente nas empresas pesquisadas predominância do modelo de administração estratégica de $\mathrm{RH}$, no qual a pessoa é mais valorizada.

GUTIERREZ (1995) apresenta a evolução da administração de $\mathrm{RH}$ da seguinte forma:

- administração de pessoal;

- administração de RH - pessoa que busca o desenvolvimento de suas potencialidades;

- administração estratégica de $\mathrm{RH}$ - pessoa como fonte de competências e recurso estratégico.

Apesar das mudanças relacionadas acima, quanto às atividades realizadas pelos psicólogos, pode-se perceber, com base nos resultados obtidos, que campos como ergonomia, segurança do trabalho, desenvolvimento de projetos relativos à saúde ocupa- 
cional são quase que totalmente inexplorados pelos psicólogos entrevistados.

Segundo SPINK (1992), o envolvimento do psicólogo no estudo das relações entre as questões de saúde mental, as agravações psicossomáticas e certas condições de trabalho é bastante recente e restrito no Brasil, ao contrário do que acontece em outras culturas. Os fatores apontados como contribuidores para tal situação são a lentidão ou o pequeno alcance do debate sobre esta temática e a tendência do psicólogo a direcionar-se "ora a uma psicologia gerencial, ora a uma prática clínica de consultório" (SPINK, 1992, p. 93) - ressaltando-se que esta "psicologia gerencial" refere-se, conforme cita ZANELLI (1994), à prática tradicional em $\mathrm{RH}$. SPINK conclui esta reflexão afirmando que "os estudos precisam continuar, porém é necessário reconhecer o débito de ação que a profissão tem para com a sociedade da qual faz parte" (1992, p. 93).

Sobre a segurança do trabalho há que se ressaltar sua importância num contexto de busca de melhoria de qualidade e o caráter contraditório de se treinar o funcionário e sensibilizá-lo para um programa de qualidade numa empresa que não se preocupa em manter condições de trabalho seguras e voltadas à prevenção de acidentes. Conforme coloca PAIVA (1992), "a lógica de estrutura na relação empresa-empregado ainda não permitiu que definitivamente se entenda que os danos provocados ao sistema de Recursos Humanos resvala para o prejuízo direto da organização, não raramente com paralisações de produção causadas por contaminações ambientais, incêndios, explosões, etc." (p. 139140).

O reduzido índice de psicólogos entrevistados envolvidos em atividades relacionadas à Saúde Mental no trabalho e à Ergonomia pode levar às hipóteses de que ou não está existindo uma abertura nas empresas para esta área de atuação, ou os referidos psicólogos não estão interessados (e até por isso mesmo não 
estão preparados para envolver-se) num trabalho desta natureza, sendo a segunda hipótese alarmante, posto que tais psicólogos não estão procurando desenvolver projetos voltados à qualidade de vida, apesar de afirmarem que sua concepção de qualidade na inter-relação entre indivíduos e organização está relacionada a este conceito. Será que estas empresas e estes psicólogos vinculados a um programa de melhoria de qualidade só estão interessados na qualidade dos processos e dos produtos?

É importante salientar que, para o nível mais amplo de atividades que vêm sendo exigidas, faz-se necessário o desenvolvimento de um novo perfil do profissional de Psicologia.

Os psicólogos envolvidos com a Qualidade elegeram como requisitos e habilidades mais importantes para o exercício de sua profissão, respectivamente: visão global do negócio; flexibilidade para atuação; capacidade de antecipar-se às mudanças; habilidades em administração de conflitos e envolvimento no planejamento estratégico.

Percebe-se que o psicólogo tem clareza das características que devem se fazer presentes numa boa atuação, mas existem muitos obstáculos a vencer entre esse processo de conscientização e sua atuação como agente de mudanças dentro das organizações.

Dentre os psicólogos entrevistados, apenas 10\% afirmaram não enfrentar nenhum entrave neste sentido. Os demais psicólogos indicaram a resistência à mudança em todos os níveis hierárquicos, como sendo o maior obstáculo a ser vencido, além de outros fatores importantes, tais como: a política da empresa; a falta de tempo do psicólogo devido ao grande número de atividades que lhe são solicitadas e a dificuldade do psicólogo em falar a mesma linguagem que a alta administração.

Clarifica-se, neste momento, a realidade de que as dificuldades que ocorrem mais freqüentemente em uma organização referem-se a fatores "humanos" e não a "processos". Este dado 
reforça a idéia que se verificou na literatura acerca da extrema importância de sensibilizar e conscientizar as pessoas para a mudança organizacional, pois toda e qualquer inovação, para se consolidar, precisa ser aceita pelas pessoas nela envolvidas ou pela organização como um todo.

Fica clara então a necessidade de o psicólogo conduzir ações com objetivo de tratar com muito cuidado o aspecto social da mudança de forma a conseguir cooperação em vez de resistência.

Fornecer informação correta e bem transmitida pode fazer com que as pessoas saibam por que mudar, como mudar e de que maneira serão atingidas pelas mudanças, percebendo então a inovação como fator de progresso e não como ameaça.

Contudo, parece que o psicólogo não está preparado para enfrentar os novos desafios que se lhe impõem.

Os psicólogos entrevistados apresentaram respostas incoerentes e contraditórias entre si, conforme pode ser constatado ao compararem-se os dados referentes à percepção que os psicólogos têm de sua atuação no programa de qualidade e à existência de pressupostos teóricos subsidiando o seu desempenho.

A maioria absoluta destes psicólogos ( $80 \%$ ) consideram sua atuação no programa de Qualidade "forte", "importante", "essencial", devido ao seu conhecimento acerca do ser humano e do seu comportamento. Também afirmam que uma atuação "ideal" de um psicólogo envolvido com a qualidade é efetivada, principalmente, pela aplicação de seus conhecimentos psicológicos, pela percepção do contexto organizacional e pela participação no programa de qualidade como um todo. Contudo, $20 \%$ destes psicólogos utilizam apenas teorias de qualidade e somente $20 \%$ revelam possuir uma teoria psicológica definida embasando sua atuação. Muitos profissionais apresentam uma "mistura" de conceitos psicológícos e organizacionais incompatíveis entre si ou errôneos. 
A "confusão" dos psicólogos pode ser observada através das afirmações expostas nos resultados, revelando profissionais que:

- ou não possuem de fato nenhum saber estruturado acerca da Psicologia - o que poderia impedir que se autointitulassem psicólogos;

- ou possuem uma concepção de ser humano distorcida, mesmo sem se darem conta disso. A utilização de "conceitos gerais da formação" (como se existisse uma Psicologia "Geral"), assim como uma atuação fundamentada numa "salada de teoria", revelam a incoerência teóricometodológica de alguns destes profissionais.

Percebeu-se, além disso, que vários entrevistados têm uma visão de que o conhecimento psicológico é o clínico e individual ou o restrito às atividades tradicionais do psicólogo (como seleção, avaliação de desempenho, ...), o que os levou a considerarem como administrativo o trabalho relacionado à mudança de cultura, a busca de resultados, o saber sobre que tipo de ferramenta utilizar, a visão ampla das questões que devem ser trabaIhadas nos treinamentos, enfim, associaram o organizacional unicamente com o administrativo.

Apesar de $80 \%$ dos psicólogos terem realizado um ou mais cursos de especialização na área organizacional, verificou-se que ainda falta consistência teórico-metodológica a estes profissionais - o que é uma realidade alarmante.

As transformações contínuas e aceleradas pelas quais as organizações estão passando exigem que os psicólogos revisem os modelos arcaicos de atuação e construam novos modelos. Neste ponto aparece uma grande dificuldade, pois sua formação é insuficiente e inadequada. A disciplina "Psicologia Industrial" (terminologia encontrada em vários cursos de Psicologia) é praticamente a única que objetiva preparar os alunos para atuarem junto às organizações e, geralmente, apenas os instrui para o desem- 
penho de atividades técnicas. Isto pode ser ilustrado pelo seguinte depoimento:

"A primeira vez que eu cheguei numa empresa me perguntaram: '- O que você sabe fazer?' Eu respondi: 'Absolutamente nada. Você estuda cinco anos pra chegar pra um gerente e dizer 'Eu não sei fazer nada', e era a realidade, eu não sabia fazer nada mesmo. (...) A gente tem uma formação muito mais clínica do que organizacional, mas a gente sai com canudo para também atuar na empresa. Então isso é uma coisa para ser revista nos currículos".

O psicólogo que não investir no autodesenvolvimento, apesar de as escolas e faculdades não estarem alertas às novas exigências mundiais do trabalho e privilegiarem a área clínica em detrimento das outras, não sairá de uma prática restrita para um papel renovado.

Este novo papel está intimamente ligado a mudanças estruturais nas organizações, propiciadoras de maior valorização do fator humano e dos conhecimentos, por parte do psicólogo, sobre o comportamento organizacional.

A atuação do psicólogo organizacional ainda pode ser considerada pequena frente às grandes oportunidades de trabalho que se abriram a este profissional com os programas de melhoria da qualidade. Sua ampliação dependerá exclusivamente da sua própria competência em ocupar este espaço. Como afirma uma psicóloga entrevistada: “... o psicólogo não pode se intimidar diante dos engenheiros, administradores, ele tem que colocar a parte dele, fazer o espaço dele, porque o espaço do administrador, do engenheiro, ja está construído. (...) Mas eu acho que a gente tem conseguido...". 


\section{CONSIDERAÇÕES FINAIS}

Os Programas de Melhoria da Qualidade visam uma mobilização para a mudança, atingindo diversos níveis hierárquicos e gerando expectativas bem variadas quanto às formas de envolvimento das pessoas com o trabalho. O participar, o pensar, o inovar são colocados em destaque.

Porém, os dados do presente estudo demonstram moderado comprometimento das pessoas das empresas pesquisadas para com o Programa de Melhoria da Qualidade, em virtude de a cultura organizacional não se modificar rapidamente.

É interessante salientar que os psicólogos entrevistados apontaram esta resistência das pessoas à mudança como sendo - maior obstáculo para exercerem seu papel de agentes de transformação. Contudo, a gestão do processo de mudança de comportamento deveria ser seu objeto de trabalho!

O fato de somente $20 \%$ dos psicólogos desenvolverem atividades voltadas à saúde mental do trabalhador revela um investimento ainda pequeno nas pessoas - que pode ser atribuído à falta de espaço ou de interesse do psicólogo em atuar nesta área.

Identifica-se, portanto, por meio da análise das atividades desenvolvidas pelo psicólogo organizacional que, perante as novas relações de produção, ele necessita ampliar sua atuação para poder desempenhar um papel mais relevante junto ao desenvolvimento das PESSOAS e, conseqüentemente, da organização.

Tal investimento na relação indivíduo-trabalho, promovendo o funcionário enquanto cidadão, seria uma ação profilática da Psicologia para a sobrevivência da empresa.

Os dados revelam que as maiores dificuldades encontradas pelo psicólogo referem-se às pessoas e não aos processos, reforçando ser o homem o diferencial neste novo contexto de trabalho, marcado pela implantação de Programas de Qualidade.

Se os psicólogos envolvidos nos Programas de Qualidade tivessem como norteadoras de seu trabalho uma consistente con- 
cepção de homem e de qualidade, contribuiriam de forma mais eficiente e integrada na dinâmica das organizações.

As conclusões deste trabalho não podem ser generalizadas para o conjunto das empresas, por questões metodológicas porém revelam que, por exigência das empresas, os psicólogos começam a romper com sua atuação limitada e fragmentada, delineando novas perspectivas de atuação para este profissional.

\section{REFERÊNCIAS BIBLIOGRÁFICAS}

1 BASTOS, A. V. B. A Psicologia no contexto das organizações: tendências inovadoras no espaço de atuação do psicólogo. In: CONSELHO FEDERAL DE PSICOLOGIA. Câmara de Educação e Formação Profissional. Psicólogo brasileiro : construção de novos espaços. Campinas : Átomo, 1992.

2 CARVALHO, A. M. A. Atuação psicológica : uma análise das atividades desenvolvidas pelos psicólogos. In: CONSELHO FEDERAL DE PSICOLOGIA. Quem é o psicólogo brasileiro? São Paulo : EDICON, 1988. p. 100-122.

3 CROSBY, P. Os 14 passos da melhoria da qualidade não terminam nunca. Folha Management, São Paulo, n. 17, 4 dez. 1995.

4 GONÇALVES, S. O. A Ética e o Psicólogo Organizacional. Documenta CRP-08, v. 2, n. 2, jan./abr. 1992.

5 GUTIERREZ, L. H. S. Recursos humanos : uma releitura contextualizada. Revista de Administração de Empresas, São Paulo, v. 35, n. 4, p. 72-82, jul./ago. 1995.

6 MALVEZZI, S. Psicologia organizacional e recursos humanos tendências e perspectivas. Cadernos CRP-06, São Paulo, p. 67-87, set. 1992 .

7 PAIVA, C. A busca da qualidade passa pela segurança no trabalho. In: RECURSOS humanos : foco na modernidade : 
textos selecionados. Rio de Janeiro : Qualitymark ED/ ABRH Rio, 1992.

8 SPINK, P. K. Saúde mental e trabalho : o bloqueio de uma prática acessível. In: CAMPOS, F.C.B. (Org.). Psicologia e saúde: repensando práticas. São Paulo : Hucitec, 1992.

9 VENTURI, E. P. C. Alguns dados sobre a atuação do Psicólogo Organizacional em Curitiba. Curitiba, 1992. Dissertação (Mestrado) - Universidade Federal do Paraná. Setor de Educação. Curso de Pós-Graduação.

10 WANDERLEY, J. A. Consultoria interna : mudança à vista. In: RECURSOS humanos : foco na modernidade : textos selecionados. Rio de Janeiro : Qualitymark ED/ABRH Rio, 1992.

11 ZANELLI, J. C. Movimentos emergentes na prática dos psicólogos brasileiros nas organizações de trabalho : implicações para a formação. In: PSICÓLOGO brasileiro : práticas emergentes e desafios para a formação. São Paulo : Casa do Psicólogo, 1994. p. 81-156. 